\title{
Microstructural Development of Green Micro-Machined, Injection-Molded Silicon Carbide
}

\author{
Richard E. Chinn ${ }^{1}$, Sundar V. Atre ${ }^{2}$, Kunal H. Kate ${ }^{2}$, Recep Onler ${ }^{3}$ and O. Burak Ozdoganlar ${ }^{3}$ \\ 1 Oregon State University, Corvallis, OR, USA, and National Energy Technology Laboratory, Albany, \\ Oregon, USA. \\ 2 Oregon State University, Corvallis, OR, USA. Currently with the University of Louisville, Louisville, \\ KY, USA. \\ ${ }^{3}$ Carnegie Mellon University, Pittsburgh, PA, USA.
}

Powder injection molding (PIM) is promising for silicon carbide fabrication of complex shapes with fine features. The feature size is limited by the particle size and process parameters such as debinding. PIM $\mathrm{SiC}$ is sintered without pressure assistance. The difficulty of sintering $\mathrm{SiC}$ without external pressure is mitigated by sintering additives such as carbon, $\mathrm{B}_{4} \mathrm{C}, \mathrm{Al}_{2} \mathrm{O}_{3}, \mathrm{MgO}$, $\mathrm{AlN}$ and $\mathrm{Y}_{2} \mathrm{O}_{3}$ [1]. Small-scale features can be formed by green micro-machining (GMM), where the green compact is shaped with a high-speed milling bit [2] [3].

The purpose of this paper is to evaluate GMM of PIM SiC before and after sintering. The effects of GMM, debinding method and particle size distribution on microstructures, phases, hardness, grain size and density are reported.

Two $\alpha$-SiC thermoplastic feedstocks were prepared and analyzed. All percentages are mass\%, except as specified. The first feedstock, Sets 1-4 in Table 1, was monomodal, with $\mathrm{D}_{50}=0.7 \mu \mathrm{m}$ and a solid fraction $\varphi=53 \mathrm{vol} \%$. The second, Sets 5-8 in Table 1, was bimodal, with $90 \%$ of the monomodal powder and $10 \%$ of a finer powder with $\mathrm{D}_{50}=20 \mathrm{~nm}$ and $\varphi=54 \mathrm{vol} \%$. The binder in both cases was $50 \%$ paraffin, 35\% polypropylene, 10\% LDPE-g-MA, and 5\% stearic acid. All the components are commercially available. Both feedstocks were PIM into $92 \times 23 \times 3$-mm tensile bars similar to Figure 1 .

The even-numbered green bars in Table 1 and Figures 1-6 were machined with a series of 0.25-mm wide grooves on one face. The odd-numbered bars in Table 1 were not machined. Bar Sets 3, 4, 7 and 8 were thermally dewaxed in a proprietary process before GMM, and the rest were solvent-dewaxed $4.0 \mathrm{hr}$ in heptane at $60^{\circ} \mathrm{C}$ [4] after GMM in Table 1 . All the bars were thermally debound and sintered at atmospheric pressure for $2.0 \mathrm{hr}$ at $2000^{\circ} \mathrm{C}$ in argon, supported in the furnace by graphite foil, and furnace cooled.

The monomodal PIM SiC was very compatible with GMM, except that the swarf adhered strongly to the substrate whether the substrate was solvent-dewaxed after GMM or thermally dewaxed (Figures 1-5) before GMM. Thermal dewaxing reduced the amount of adhering swarf and sintering distortion but did not completely eliminate either. Bimodal PIM SiC in Figure 6 was much less compatible with GMM than monomodal, except that swarf adhesion was not a problem. All compositions and treatments were densified to closed porosity, with 17-20\% shrinkage in each dimension. Thermal dewaxing of bimodal bars, Sets 7 and 8 in Table 1, resulted in feature distortion, excess grain growth, weak bonding and low hardness [5]. 


\begin{tabular}{|c|c|c|c|c|c|c|c|}
\hline \multirow{2}{*}{ Set No. } & \multirow{2}{*}{$\begin{array}{l}\text { Particle Size } \\
\text { Distribution }\end{array}$} & \multirow{2}{*}{$\begin{array}{l}\text { Dewaxing } \\
\text { Method }\end{array}$} & \multirow{2}{*}{ GMM? } & \multirow{2}{*}{$\begin{array}{c}\text { Density } \\
\text { (\% ideal) }\end{array}$} & \multicolumn{2}{|c|}{ HKN (GPa) } & \multirow{2}{*}{$\begin{array}{c}\text { GS } \\
(\mu \mathrm{m})\end{array}$} \\
\hline & & & & & GMM & Bulk & \\
\hline 1 & \multirow{4}{*}{ Monomodal } & \multirow{2}{*}{ Solvent } & No & 94.9 & - & 14.6 & 0.56 \\
\hline 2 & & & Yes & 95.2 & 14.5 & 14.3 & 0.52 \\
\hline 3 & & \multirow{2}{*}{ Thermal } & No & 96.1 & - & 14.0 & 0.69 \\
\hline 4 & & & Yes & 96.6 & 13.7 & 14.4 & 0.59 \\
\hline 5 & \multirow{4}{*}{ Bimodal } & \multirow{2}{*}{ Solvent } & No & 97.0 & - & 14.9 & 0.70 \\
\hline 6 & & & Yes & 96.8 & 14.2 & 15.5 & 0.79 \\
\hline 7 & & \multirow{2}{*}{ Thermal } & No & 98.3 & - & 9.59 & 2.7 \\
\hline 8 & & & Yes & 99.2 & 10.1 & 9.07 & 3.0 \\
\hline
\end{tabular}

Table 1: Green processing and sintered properties of PIM SiC tensile bars.

$\begin{array}{ll}\text { 4, Set } 4, & \begin{array}{l}\text { Figure 2: GMM bar, Set } \\ \text { before sintering. }\end{array} \\ \text { Figure 1: GMM bar, } \\ \text { before sintering. }\end{array}$

\section{References}

[1] R. E. Chinn, et al., Euro PM2015 - Advanced Materials and Applications 2 (2015) p. 1.

[2] J. Z. Li, et al., Journal of Materials Processing Technology, 212, (2012) p. 571- 579.

[3] R. E. Chinn, et al., Proceedings of PowderMet 2015 (2015) p. 59.

[4] V. P. Onbattuvelli, et al., Ceramics International, 40, p. 13861-13868, 2014.

[5] The authors acknowledge funding from the National Science Foundation, Award \# CMMI 1200144. The authors thank Mr. P.E. Danielson of NETL for his assistance with the microstructure photography. 